

\title{
ANÁLISE ENVOLTÓRIA DE DADOS PARA AVALIAÇÃO DIAGNÓSTICA DE EFICIÊNCIA NO CULTIVO DE TILÁPIAS
}

\author{
DATA ENVELOPMENT ANALYSIS FOR DIAGNOSTIC EVALUATION IN THE TILAPIA \\ CULTIVATION
}

Omar Jorge Sabbag ${ }^{1}$

Renata Melon Barroso Bertolini²

Rayner Sversut Barbieri ${ }^{3}$

1 Pós-Doutor e Professor Associado III (Área: Gestão do Agronegócio)

Faculdade de Engenharia de Ilha Solteira-FEIS/UNESP Ilha Solteira/SP - Brasil. omar.sabbag@unesp.b

2 Pós-Doutora em Aquicultura - Washington State University - Superintendência Federal da Agricultura/RS (Gabinete)

Porto Alegre/RS - Brasil

renata.barroso@agricultura.gov.br

3 Professor Doutor

Departamento de Zootecnia das Faculdades Associadas de Uberaba - FAZU

marlon.soliman@ufsm.br

Recebido em: 16 set. 2020

Aprovado em: 15 nov. 2020
Resumo: No ambiente produtivo, torna-se relevante avaliar o desempenho de uma determinada unidade produtiva. Este trabalho objetivou analisar a eficiência mensal do sistema de cultivo em uma propriedade piscícola em 2018. Metodologicamente, foi aplicada a técnica de Análise Envoltória de Dados, tomando como variáveis explicativas para insumos os custos com insumos, ração consumida, taxa de conversão alimentar, biomassa final e descarte de animais; para o output (resultado) considerado foi a produção. Observou-se que $67 \%$ dos meses de cultivo possuem eficiência acima de $90 \%$ em relação ao conjunto de variáveis estudadas. Verificou-se que o período mensal com menor desempenho deve minimizar o uso dos insumos em $34,7 \%$ para tornar eficiente. Conclui-se que a adoção de boas práticas zootécnicas, como o manejo da ração, poderá servir como diretriz ao gestor em sua atividade piscícola, na expectativa de resultados positivos, inferindo que a eficiência em sua concepção teórica reflete em produzir mais com menos, sob a ótica da otimização de recursos.

Palavras-chave: Análise DEA. Desempenho produtivo. Modelo CCR.

Abstract: In the production environment, it is relevant to evaluate the performance of a given production unit. This paper aimed to analyze the month efficiency of the cultivation system in a fish farming in 2018. Methodologically, the Data Envelopment Analysis technique, taking as input explanatory variables the costs of inputs, consumed feed, feed conversion rate, final biomass and animal disposal; for the output (result) concerned was production. It was observed $67 \%$ of the months of cultivation have efficiency above $90 \%$ in relation to the set of variables studied. It was found that monthly period should minimize the use of inputs by $34.7 \%$ to be efficient. It is concluded that the adoption of good zootechnical practices, such as the management of feed may serve as a guideline to the manager in his fish activity, in the expectation of positive results, inferring that the efficiency in his theoretical conception reflects in producing more with less, under the optics of resource optimization.

Keywords: DEA analysis. Production performance. CCR model. 


\section{Introdução}

O Brasil produziu 722.560 toneladas de peixes de cultivo em 2018, com crescimento de 4,5\% sobre as 691.700 toneladas do ano anterior (Peixe $\mathrm{Br}$, 2019). Destaca-se ainda que a piscicultura brasileira é uma atividade em crescimento e com grande potencial devido aos recursos hídricos do país, às dimensões continentais, ao clima propício e à capacidade empreendedora dos produtores.

A produtividade de tilápia no país está relacionada ao melhoramento genético, padrão de qualidade da ração, adequação do manejo no ambiente produtivo, bem como a inserção de novas tecnologias (Sussel, 2015). Por outro lado, a redução nos índices de produtividade na tilapicultura podem decorrer do baixo nível de eficiência em uma unidade piscícola, podendo imprimir elevação de custos e, consequentemente, redução da competitividade para um mercado promissor, conforme mencionado por Brunetta (2004).

No ambiente produtivo, deve-se ampliar o conceito de gestão técnica nas propriedades piscícolas, não limitado apenas ao controle de custos e ganhos de uma atividade. Neste sentido, é fundamental analisar alguns parâmetros zootécnicos no processo de produção, tais como a taxa de conversão alimentar, inferindo na importância de avaliar a eficiência nos sistemas produtivos aquícolas.

Segundo Gomes et al. (2005), a avaliação da eficiência dos sistemas produtivos gera informações relevantes que permitem, aos gestores, comparar unidades produtivas entre si, avaliar a alocação dos recursos disponíveis para produção e determinar a produção possível de ser atingida.

Neste contexto, o termo eficiência, apesar de ser usado como sinônimo para produtividade, é um conceito muito particular e distinto de produtividade. A eficiência é uma forma de construir vantagens competitivas, identificar as origens e quantificar a ineficiência em cada insumo utilizado. De modo geral, existe grande heterogeneidade tecnológica e produtiva gerada pelas variáveis interrelacionadas em unidades agropecuárias, determinando níveis de eficiência muito distintos (Pereira \& Silveira, 2016).

A utilização dessas múltiplas interações em um ambiente produtivo e as relações entre essas variáveis pode ser medida pela análise envoltória de dados (data envelopment analysis - DEA). Assim, a DEA é um instrumento de avaliação de desempenho de diferentes tipos unidades de produção, que possibilita enxergar aquelas que podem ser mais ou menos eficientes (Bisso et al., 2016).

Dessa forma, torna-se relevante avaliar a eficiência técnica de uma determinada unidade produtiva, considerando que a variação entre os lotes produtivos possa resultar em diferentes classes de eficiência, pressupondo assim melhor uniformização no sistema produtivo, os quais determinados lotes possam servir de referência em detrimento aos demais com escores de eficiências inferiores à unidade. 
Considerando a importância estratégica da eficiência, por meio da análise DEA, o trabalho em si pretende ser de grande relevância ao contribuir para o suprimento da lacuna existente na tilapicultura, reforçada pela revisão de literatura e resultados com foco de análise do desempenho produtivo.

Diante do exposto, este trabalho teve por objetivo analisar a eficiência do sistema de cultivo em uma propriedade com sistema intensivo, demonstrando a aplicação da metodologia DEA em um sistema de produção piscícola referente ao ano de 2018, com vistas a verificar o grau de eficiência produtiva entre os meses de cultivo.

\section{Referencial Teórico}

\subsection{Tilapicultura e análise de eficiência}

O Brasil produziu 400.280 toneladas de tilápia em 2018, com crescimento de 11,9\% em relação ao ano anterior. Com esse desempenho, a espécie representa 55,4\% da produção total de peixes de cultivo e o país mantém a 4a posição mundial, atrás da China, Indonésia e Egito (Peixe Br, 2019), conforme Figura 1.

Ainda assim, o Estado de São Paulo desponta como um dos polos mais eficientes do território nacional para produção de peixes de cultivo, não somente a despeito dos números (73.200 t em 2018), conforme a Peixe $\mathrm{Br}$ (2019), mas também em iniciativas de fomento às pesquisas científicas, aplicação de tecnologias (dentre as quais uso de vacinas e sistemas de automatização em comedouros), bem como incentivos oriundos de políticas públicas que facilitem a outorga de uso para pequenos e médios produtores.

\section{Figura 1}

Principais Países Produtores de Tilápia (Milhões T), 2019

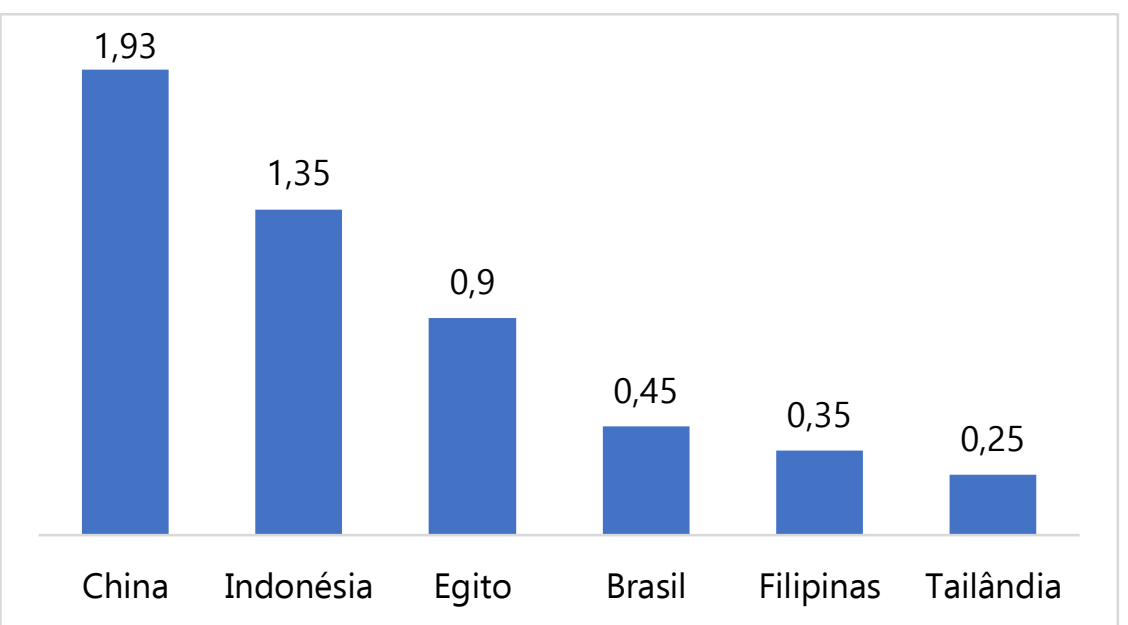

Fonte: Adaptado de Peixe BR, 2019. 
A tilapicultura brasileira possui importantes polos produtivos. No Estado de São Paulo, o maior polo de produção de tilápias está localizado no noroeste paulista, principalmente na região de Santa Fé do Sul e Ilha Solteira, nos reservatórios do rio Paraná, rio Grande e do baixo rio Tietê (Sussel, 2011), prevalecendo até os dias atuais como um dos principais polos de tilapicultura do país.

De maneira geral, o volume de produção nos principais polos tilapicultores do país vem crescendo ano a ano, acompanhando a evolução do total nacional (Ribeiro et al., 2005). No polo de llha Solteira (noroeste paulista), houve um aumento de 35\% no período 2014-2015, passando de $20.000 \mathrm{t}$ para 27.000 t (Embrapa, 2018).

É importante enfatizar que a eficiência produtiva não está associada exclusivamente à aplicação de alta tecnologia. A baixa produtividade pode ocorrer por uma alteração no indicador de eficiência ou no indicador de eficiência tecnológica, de maneira que é possível reconhecer a natureza dessas mudanças e buscar a compreensão do que poderia impactar mais a produção (Araujo Neto, 2016).

Assim, sem ampliação do acesso à tecnologia moderna e certificação de aplicação das tecnologias menos onerosas (como simples biometria a anotação de coeficientes zootécnicos e econômicos), a vasta maioria dos tilapicultores de pequeno e médio porte dificilmente sobreviverão a tais contextos, remetendo à importância de analisar a eficiência e a consequente evolução da produtividade desta importante atividade econômica para o setor aquícola no país.

O método de Análise Envoltória de Dados é um método que tem sido amplamente usado nos mais variados estudos sobre eficiência das Unidades Tomadoras de Decisão (DMU's - decision making units). Destaca-se que a técnica DEA foi desenvolvida por Charnes, Cooper e Rhodes (1978) com base nos conceitos de eficiência de Farell (1957), ou seja, tem a característica de comparar as unidades para determinar a eficiência técnica para cada unidade avaliada, sendo que as DMU's podem ser classificadas em unidades eficientes e ineficientes.

Este método tem fornecido informações mais precisas acerca das atividades, representando um avanço na análise de eficiência, ou seja, é um método que assume que nem todas as empresas são eficientes, havendo a estimativa de fronteiras de eficiências, em que a análise das firmas é relativa à fronteira. O método DEA pode ser aplicado em casos de múltiplos insumos e múltiplos produtos e tem como característica a vantagem de poder identificar as origens e quantificar a ineficiência em cada insumo e cada produto para cada parte da empresa e identificar os membros referência (Pereira \& Silveira, 2016).

Assim, a técnica DEA é representada por meio de um fluxograma (Figura 2), com as principais etapas e condicionantes, proposto por Ângulo Meza et. al. (2005), para a modelagem em suas três principais etapas. 
Figura 2

Principais Etapas de Aplicação da Técnica DEA

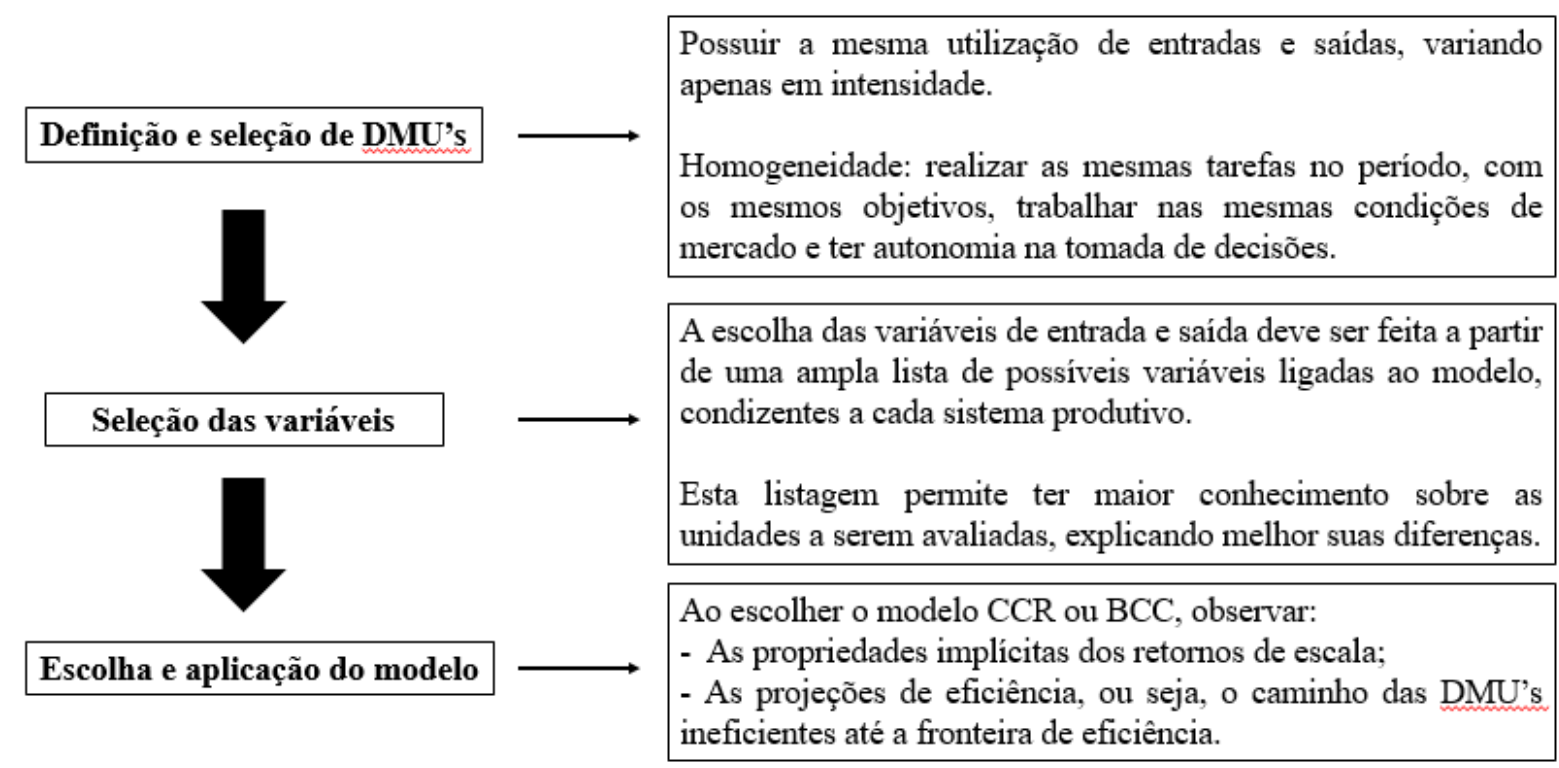

Fonte: Adaptado de Ângulo Meza et al. (2005).

A técnica não paramétrica ${ }^{1}$ desenvolvida por Charnes, Cooper e Rhodes (1978), precedido por Farell (1957), tem como propósito não apenas comparar as unidades em seu nível de eficiência técnica, mas também permite determinar a eficiência de uma unidade produtiva comparativamente às demais, considerando-se os múltiplos insumos utilizados e os múltiplos produtos gerados (Zubyk et al., 2019).

Assim, caso o desempenho da DMU esteja sobre a curva ou fronteira de eficiência, ela é tida como tecnicamente eficiente; caso contrário, é tecnicamente ineficiente. Conforme Azambuja (2002), a única condição é que todas as DMU's tenham uma eficiência menor ou igual a 1, em que Effo é a eficiência da $\mathrm{DMU}_{0}$; uj e iv são os pesos de outputs j e inputs i, respectivamente; ik x e jk y são os inputs i e outputs j da DMUk e; i0 x e j0 y são os inputs i e outputs j da DMU0, conforme expressão a seguir.

$$
\begin{gathered}
\operatorname{MaxEff_{0}}=\frac{\sum_{j=1}^{s} U_{j} Y_{j 0}}{\sum_{i=1}^{m} V_{i} X_{i 0}} \text { sujeito à: } \\
\frac{\sum_{j=1}^{S} U_{j} Y_{j k}}{\sum_{i=1}^{m} V_{i} X_{i k}} \leq 1, k=1,2, \ldots, n
\end{gathered}
$$

Destaca-se que o presente modelo possui inicialmente infinitas soluções e que desta forma, deve ser transformado sequencialmente em problema de programação linear matemática (PPL), cada

\footnotetext{
1 A vantagem do método não paramétrico (técnica de programação linear) deve-se a simplificação deste em relação às exigências e pressuposições com relação aos paramétricos, viabilizando, desta forma, pesquisas de temas relevantes para a piscicultura em questão.
} 
qual com uma única solução, denominado como modelo primal (Casado \& Siluk, 2011) e posteriormente em dual ou envoltório, como é conhecido pela própria denominação atribuída à técnica de análise.

De acordo com Marinho (2001), as vantagens do DEA em relação a outras técnicas de análise de eficiência se justificam pelas suas características, dentre as quais: a) a de caracterizar cada DMU como eficiente ou ineficiente através de uma única medida resumo de eficiência; b) não fazer julgamentos a priori sobre os valores das ponderações de inputs e outputs que levariam as DMU's ao melhor nível de eficiência possível; c) basear-se em observações individuais e não em valores médios; e d) permitir a observação de unidades eficientes de referência (benchmarking) para aquelas que forem assinaladas como ineficientes.

Por outro lado, algumas limitações da técnica DEA podem ser listadas, dentre as quais: à medida que cresce o número de variáveis, aumenta também a chance de mais unidades alcançarem o desempenho máximo; por constituir de uma técnica não paramétrica, torna-se difícil formular hipóteses estatísticas (Dyson et al., 2001).

Segundo Jorge et al. (2010), as principais finalidades da análise de eficiência DEA se resumem em evidenciar as causas e a dimensão da ineficiência relativa de cada DMU comparada; gerar um indicador de eficiência; e determinar novas metas de produção que maximizem a eficiência das DMU's.

Destaca-se que ao longo dos anos, a técnica DEA apresentou inúmeras aplicações para os mais diversos setores produtivos, dentre os quais bancos, educação, meio ambiente e produção industrial e agrícola (Paiva Júnior, 2000), propiciando melhores condições em nível de controle produtivo sobre a utilização de recursos.

$\mathrm{Na}$ aquicultura, Torres et al. (2017) diagnosticaram o nível de eficiência dos piscicultores próximos a Dourados/MS na execução das atividades, gerando subsídios para o crescimento da prática na região. Os autores perceberam a possibilidade de um incremento para os produtores ineficientes (em detrimento com apenas $11,7 \%$ de produtores eficientes), por meio da gestão, sendo possível a reorientação do piscicultor para o melhoramento de sua atividade.

Silva Neta et al. (2016) utilizaram a DEA para estabelecer um planejamento de produção e venda escalonadas de tilápia, com aproveitamento econômico das vísceras para os piscicultores do Castanhão/CE, demonstrando que esse tipo de estudo pode ser usado como referência para mercados e feiras públicas dos municípios da região. No presente estudo, como proposição, o produtor pode maximizar seus resultados e minimizar seus custos, a partir de um melhor planejamento, execução e controle do seu negócio, aliado à eficácia do empreendimento, relacionada às mudanças da postura gerencial, em que ao adotar um gerenciamento de qualidade, os processos e produtos poderão se tornar mais competitivos para conquistar novos mercados.

Segundo Alves Junior et al. (2018), um ponto que deve ser considerado é a homogeneidade das DMU's para avaliação de eficiência. As variáveis devem ser as mesmas para todas as DMU's, procurando 
obter resultados que não apresentem problemas de empate ou setores que sejam muito superiores. De outra forma, o modelo proposto considerado melhor para medir a eficiência de sistemas produtivos aquícolas deve possuir variáveis com relações entre si.

Neste contexto, o presente estudo tem como proposição de que o gerenciamento da atividade piscícola com a intensificação dos sistemas de produção pode contribuir para aumentar a produção (Matos, 1996), que infere na melhor eficiência do sistema produtivo, e que será objeto de investigação a ser testado, considerando os principais alvos a serem supostamente alcançados para melhoria do desempenho em relação às variáveis de análise.

\section{Material e métodos}

A presente pesquisa caracterizou-se como amostra não aleatória, do tipo intencional, na qual a amostra é escolhida intencionalmente pelo pesquisador, conforme mencionam Marconi e Lakatos (1996), referente aos dados mensais de cultivo para um empreendimento voltado à produção de tilápias no ano de 2018. Neste sentido, após a compilação dos dados na plataforma Microsoft Excel, os mesmos foram submetidos à técnica não paramétrica, por meio da análise envoltória de dados.

Ressalta-se que é um tipo de pesquisa categorizado como um estudo de caso, que tem como objeto o estudo de uma unidade de forma aprofundada, podendo tratar-se de um sujeito, grupo de pessoas, comunidade, dentre outros (Prodanov \& Freitas, 2013), com aspecto qualitativo e/ou quantitativo.

O sistema produtivo do empreendimento avaliado é destinado à produção e comercialização de tilápias (Oreochromis spp.) - sistema de engorda com a aquisição de juvenis vacinados com 30g, localizado em Santa Clara D'Oeste, região Noroeste Paulista, com área de 4,5 hectares (lâmina d'água) em área total de propriedade de 3,6 hectares, com atuação nas atividades desde 2007. Atualmente possuem 210 milheiros distribuídos em 554 tanques de 3×3×2,20 m, com produção estimada em 174 t/mês, com 18 funcionários.

A alimentação é realizada 3x/dia (sendo dois tratos no período matutino e um trato no período vespertino), com a retirada diária de peixes mortos. A classificação dos peixes é efetuada em diferentes tamanhos (GG - este considerado o melhor peixe em tamanho; cabeceira; médio e rabeira, sendo este último descartado), com clientes compradores de frigoríficos e Ceagesp - São Paulo. Após a retirada dos peixes (para fins de classificação ou despesca), é efetuada a limpeza, desinfecção e manutenção nos tanques-redes.

Convém destacar que a equipe de colaboradores nesta unidade piscícola atua em diferentes áreas, dentre as quais: comercial, despesca, alimentação e classificação. 
Assume-se que o sistema de produção é pautado em um mesmo padrão tecnológico (produção em tanques-redes de forma intensiva). Em função de alguns parâmetros zootécnicos médios de produção, o peso médio final considerado para os padrões regionais varia entre $900 \mathrm{~g}$ e $1.000 \mathrm{~g}$, dependendo do comprador, para um período de criação em torno de 7 meses, com uma conversão alimentar mínima mensal de 1,46 e máxima mensal de 2,42 para o ano de 2018; e taxa de sobrevivência de aproximadamente $98 \%$ na fase final do ciclo de cultivo.

Neste contexto, foram utilizados dados provenientes de observações médias mensais correspondentes às variáveis de estudo, semelhante ao trabalho de Oliveira (2008), baseando-se em 12 meses de avaliação (DMU's) para os cultivos no empreendimento piscícola, suficientes para que a análise tenha resultados satisfatórios, de acordo com Ali e Seiford (1993), devendo o número de cultivos ser ao menos duas vezes o número de insumos (inputs - $\mathrm{X}$ ) e de produtos (outputs - $\mathrm{Y}$ ) para um número de unidades maior que dois $(X+Y)$, sugerindo uma análise mínima condizente com o presente estudo, devendo constituir de certa homogeneidade entre elas, por utilizarem insumos semelhantes para produzirem os mesmos e terem certa autonomia na tomada de decisão, encaixando-se perfeitamente nas definições de DMU's a serem analisadas pela técnica DEA.

A análise de eficiência realizada nesse trabalho utilizou o modelo de Análise Envoltória de Dados (DEA) por meio do software Data Envelopment Analysis Program (DEAP 2.1), desenvolvido por Coelli (1996).

O modelo adotado foi o DEA-CCR (CRS) ou variável constante de escala, por apresentar mais discriminante em relação às DMU's eficientes e não eficientes. Neste caso, o mesmo pressupõe avaliar a eficiência total (global), identificar as DMU's eficientes e/ou ineficientes, bem como determinar a que distância da fronteira de eficiência estão às unidades ineficientes, para mensurar o cálculo equidistante para alcançar a eficiência em sua unidade.

Neste contexto, o modelo constante de escala utilizado para calcular o indicador da eficiência produtiva ${ }^{2}$; ou seja, se uma unidade é considerada eficiente do ponto de vista da eficiência produtiva, ela servirá de referência (benchmark) para as demais unidades. A partir do modelo de retornos constantes, é possível a realização de uma análise de eficiência mais discriminante em relação às DMU's eficientes e não eficientes, considerando as quantidades de insumos aplicados em comparação ao valor produzido.

Foram utilizadas seis variáveis, correspondentes aos insumos $(k=5)$, e uma relacionada com produtos ( $m=1)$, conforme Tabela 1.

\footnotetext{
${ }^{2}$ Habilidade de evitar desperdícios produzindo tantos resultados quanto os recursos utilizados permitem; ou utilizando o mínimo de recursos possível para uma dada produção.
} 


\section{Tabela 1}

Variáveis Input e Output Utilizadas Para o Referido Estudo de Caso DEA

\begin{tabular}{ll} 
Variáveis & Descrição \\
\hline Input 1 & Custos com insumos: vacinas, alevinos e juvenis - $\mathrm{R} \$^{3}$ \\
Input 2 & Ração consumida mensal $(\mathrm{kg})$ \\
Input 3 & Taxa de conversão alimentar (\%): razão entre a ração consumida e a biomassa gerada \\
& $(\mathrm{kg})$ \\
Input 4 & Biomassa final mensal ( $\mathrm{kg})$ \\
Input 5 & Descarte mensal de animais $(\%)$ : número de mortes e animais não vendidos \\
Output 1 & Produção, referente às vendas mensais em $\mathrm{kg}$
\end{tabular}

Fonte: Dados da pesquisa.

Ressalta-se que o modelo CCR orientado a input foi adotado para a avaliação de eficiência, considerando que um dado nível de output é obtido com a quantidade mínima de entrada (insumos) e inferindo que se algum input ou output o peso for zero, significa que essa variável não foi considerada na avaliação.

Assim, procurou-se verificar os índices ideais para cada cultivo não eficiente, para que o mesmo pudesse atingir eficiência de 100\%; ou seja, uma análise que indique a redução de inputs necessária para que cada DMU se torne eficiente.

Para fins de critério de "desempate" para as DMU's que apresentaram "benchmarking" na eficiência padrão, ou seja, unidades que sirvam de referências às práticas adotadas as unidades não eficientes, foi calculada a eficiência composta normalizada (composta*), com o auxílio do software SIAD - versão 3.0 (Sistema Integrado de Apoio à Decisão), apresentado por Ângulo Meza et al. (2005), dividindo-se o valor da eficiência composta pelo maior valor entre todos os valores de eficiência composta, como segue a equação:

$$
\text { Eficiência Composta }{ }^{*}=\frac{\text { Eficiência composta }}{\text { Máximo (eficiência composta) }}
$$

\section{Resultados}

Inicialmente, são apresentadas as estatísticas descritivas das variáveis de análise de eficiência da propriedade piscícola (Tabela 2). Os resultados a presentam custos totais médios com insumos (como vacinas e alevinos) em $R \$ 135.953,18$, com amplitude de $R \$ 141.867,87$, sugerindo um coeficiente de

\footnotetext{
${ }^{3}$ Vale destacar que o custo com ração não foi computado, inferindo que a quantidade de ração consumida pressupõe gastos expressivos que refletem no desempenho da atividade piscícola.
} 
variação (CV) de 29,5\%, bem como o descarte de animais (coeficiente de variação de 66,5\%), justificando-se assim a amplitude de variação da produção, entre a produção mínima de 93.918 kg e máxima em 190.282 kg mensais.

Tabela 2

Estatística Descritiva das Variáveis de Estudo, 2018

\begin{tabular}{llllll}
\hline Variáveis (I/O) & Unid & Média & $\begin{array}{l}\text { Desvio } \\
\text { Padrão }\end{array}$ & Mínimo & Máximo \\
& & & & \\
\hline Custo Insumos (I1) & $\mathrm{R} \$$ & $135.953,18$ & $40.228,27$ & $95.522,70$ & $237.390,57$ \\
Consumo ração/mês (I2) & $\mathrm{kg}$ & $269.700,83$ & $24.924,98$ & $231.445,00$ & $305.980,00$ \\
Taxa (conversão) CA (I3) & $\%$ & 1.70 & 0.27 & 1.46 & 2.47 \\
Biomassa final/mês (I4) & $\mathrm{kg}$ & $616.714,83$ & $101.068,79$ & $473.603,00$ & $722.028,00$ \\
Descarte mensal (I5) & $\mathrm{kg}$ & $39.206,75$ & $26.077,67$ & $17.900,00$ & $103.242,00$ \\
Produção mensal (O1) & $\mathrm{kg}$ & $153.603,66$ & $32.679,30$ & $93.918,00$ & $190.282,00$ \\
\hline
\end{tabular}

Fonte: Dados da pesquisa.

Observa-se que há uma distribuição desuniforme entre os coeficientes de variação (CV), oriundos da relação entre o desvio padrão e a média de cada variável estudada. Destaca-se que o CV é uma medida importante sobre a variabilidade dos resultados experimentais (Pimentel-Gomes, 2009), e que para a especificidade deste trabalho, supostamente inferem em diferentes classes de eficiência.

A Tabela 3 apresenta a distribuição dos meses de cultivo na unidade piscícola por classe de eficiência no modelo DEA-CCR, permitindo classificá-los entre eficiente e ineficiente. A classe de eficiência 0,9-1 identifica oito meses, com 66,7\% da amostra (sendo 75\% deste período com eficiência técnica em 100\%), dos quais foram eficientes com maior expressividade com custos de insumos e consumo de ração, inferiores respectivamente em quantidade de uso de $29 \%$ e $3 \%$ comparativos à classe de 80 a $89 \%$ de eficiência, bem como demonstrou valores superiores em sua conversão alimentar (CA), biomassa final mensal e produção em 3,5\%, 6,9\% e 5,7\% comparativos para esta mesma classe. 
Tabela 3

Distribuição por Classe de Eficiência no Modelo DEA-CCR para as Variáveis Inputs e Output, 2018

\begin{tabular}{lllllll|l|l|}
\hline $\begin{array}{l}\text { Classe de } \\
\text { eficiência }\end{array}$ & $\%$ & 11 & 12 & 13 & 14 & 15 & 01 \\
\hline $0,60-0,699$ & 8,33 & $129.477,37$ & $302.055,00$ & 1.52 & $612.860,00$ & $18.388,00$ & 97.749 \\
\hline $0,70-0,799$ & 8,33 & $97.562,23$ & $239.680,00$ & 1.46 & $480.781,00$ & $18.079,00$ & 93.918 \\
$0,80-0,899$ & 16,67 & $183.311,49$ & $276.205,00$ & 1.70 & $597.585,00$ & $43.490,50$ & 157.916 \\
$0,90-1,000$ & 66,67 & $129.721,96$ & $267.783,12$ & 1.76 & $638.970,87$ & $43.379,12$ & 166.968 \\
\hline
\end{tabular}

Fonte: Autoria própria.

Vale ressaltar que em função de algumas relações existentes, dentre as quais consumo de ração/produção, custos de insumos/produção e animais descartados/produção, os cultivos apresentados como eficientes obtiveram valores inferiores à média. Por exemplo, para a DMU 8 (representado pelo cultivo em agosto de 2018), o mesmo apresentou 100\% de eficiência, decorrente de uma relação descarte/produção reduzida em $52 \%$ comparativo à média dos meses de cultivo, bem como um consumo de ração inferior em $20,54 \%$ em relação ao ano produtivo.

De acordo com a Figura 3, a distribuição da eficiência técnica por DMU no modelo CCR-input é expressa por percentuais de eficiência técnica das unidades de produção, classificando como eficientes os cultivos que tiveram melhor racionalização dos gastos e parâmetros zootécnicos produtivos, mantendo-se constante a produção. De maneira geral, a média foi de $92,7 \%$ entre os cultivos no ano de 2018 para o modelo CCR-input.

Assim, na análise de benchmark para os cultivos mensais analisados, identifica-se que as DMU 4, 7, 8, 9, 10 e 12 (representados pelos meses de Abril, Julho, Agosto, Setembro, Outubro e Dezembro) são pares de excelência para os demais cultivos mensais, entendidas como ineficientes, em função da representatividade dos pesos atribuídos de cada DMU eficiente à distância da fronteira. Considerandose a eficiência composta normalizada, como critério de desempate, a DMU 8 (cultivo no mês de agosto) obteve o melhor desempenho, considerando-se que além da maior produção mensal obtida, possuiu esta um menor número de descarte de peixes mortos e valores bem inferiores para a relação ração/produção ou próximos à média para insumos/produção. 
Figura 3

Distribuição da Eficiência Técnica Por DMU no Modelo DEA CCR (input), Com Destaque Para os Lotes Mensais Eficientes (Eficiência = 1), 2018

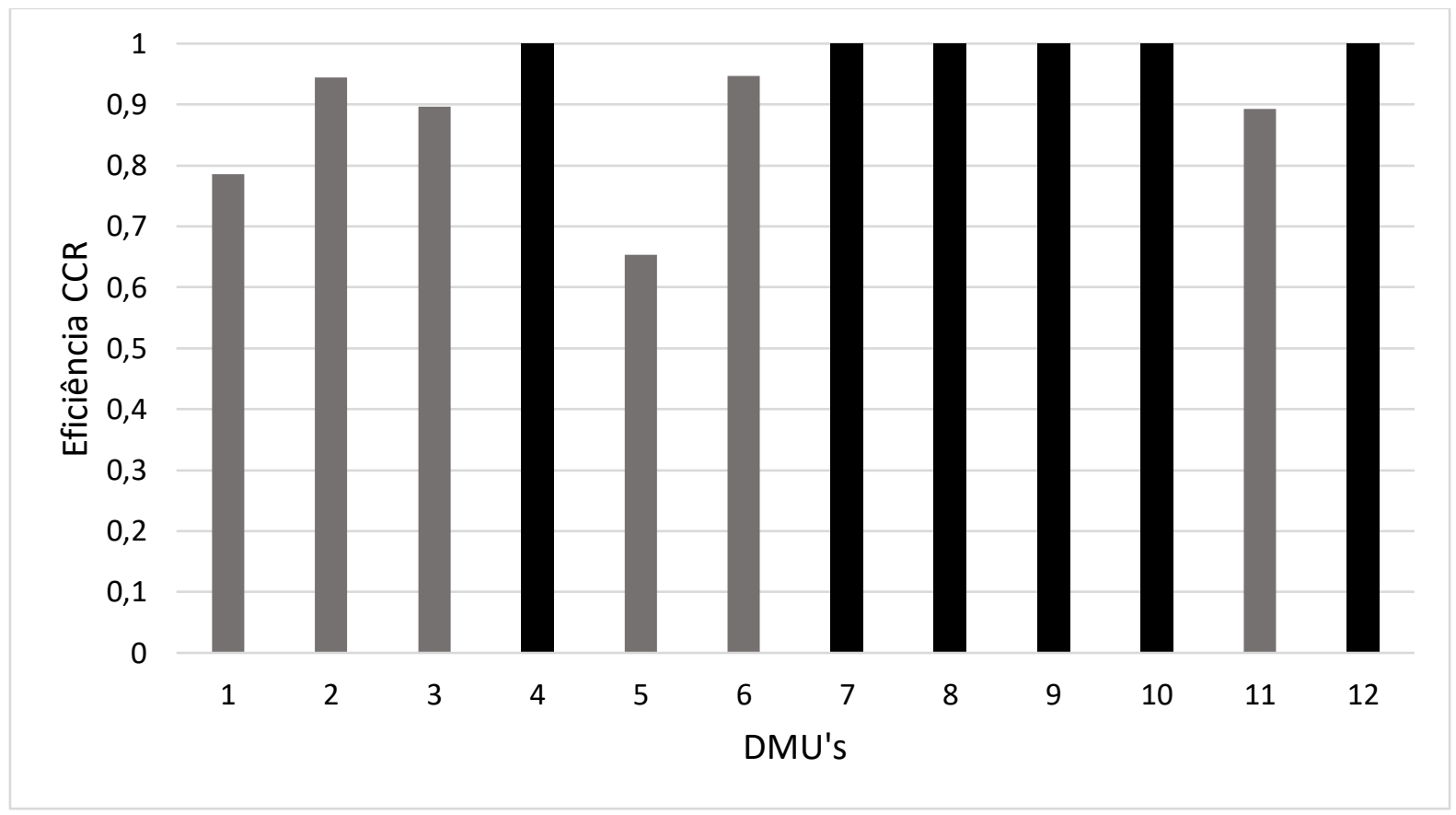

Fonte: Autoria própria.

A Tabela 4 resume os indicadores para as diferenças entre os dados atuais e os alvos a serem atingidos, para que se possam tornar eficientes por DMU (cultivo) segundo o modelo constante de escala orientado aos insumos, que explica a diferença de desempenho entre os meses do ano. Por exemplo, a DMU 5, com menor eficiência global, deve reorientar seu planejamento para reduzir o uso de insumos de maneira proporcional à produção obtida, em aproximadamente 35\% para o conjunto de inputs considerados, apresentando resultados mais distantes dos valores atuais. Desta forma, os alvos indicam para esta DMU uma projeção de custos com insumos (I1) em $\mathrm{R} \$ 84.624,39$; consumo de ração (I2) em R\$153.782,65 e descarte de animais (I5) em 12.018 kg mensais, mantendo a produção na mesma magnitude.

\section{Tabela 4}

Alteração dos Valores Atuais das Variáveis das DMU's Mais Ineficientes, Para Que se Tornem Eficientes, 2018

\begin{tabular}{cccccc}
\hline DMU & Variáveis (Inputs) & Valor Atual & Folgas & Alvo & $\Delta \%$ \\
\hline \multirow{2}{*}{$1(0,785)$} & 11 & $97.562,23$ & - & $76.653,66$ & \\
& 12 & $239.680,00$ & $29.904,45$ & $158.409,71$ & \\
& 13 & 1.46 & 0.24 & 0.90 & $-21,5$ \\
\hline
\end{tabular}




\begin{tabular}{cccccc}
\hline DMU & Variáveis (Inputs) & Valor Atual & Folgas & Alvo & $\Delta \%$ \\
\hline & 14 & $480.781,00$ & - & $377.744,81$ & \\
& 15 & $18.079,00$ & - & $14.204,48$ & \\
$5(0,653)$ & 11 & $129.477,37$ & - & $84.624,39$ & \\
& 12 & $302.055,00$ & $43.635,78$ & $153.782,65$ & \\
& 13 & 1.52 & 0.12 & 0.86 & $-34,7$ \\
& 14 & $612.860,00$ & $2.466,94$ & $398.088,79$ & \\
& 15 & $18.398,00$ & - & $12.018,11$ & \\
\hline
\end{tabular}

Fonte: Autoria própria.

A Figura 4 apresenta a relação insumos/ração/produção entre os meses de cultivo analisados, destacando que a DMU 5 (mês de maio) com menor índice de eficiência (ou desempenho), resultante da análise multiatributo das variáveis input, apresentou maior consumo de ração, bem como foi ocasionado pela menor produção mensal para 2018.

Convém destacar que o mês de maio sucedeu ao período da Páscoa, possuindo uma redução no mercado de consumo, aliado à queda dos preços da tilápia, o que limitou a produção, bem como agravado pela greve de caminhoneiros, fortalecendo a crise. Em complemento ao fato, o alto consumo da ração foi justificado pelo estoque existente de peixes nos tanques-redes, para não comprometer o ciclo de engorda ao longo dos meses subsequentes, com maior produção.

Figura 4

Relação Insumos/Ração/Produção Para o Conjunto de DMU's Analisados, 2018

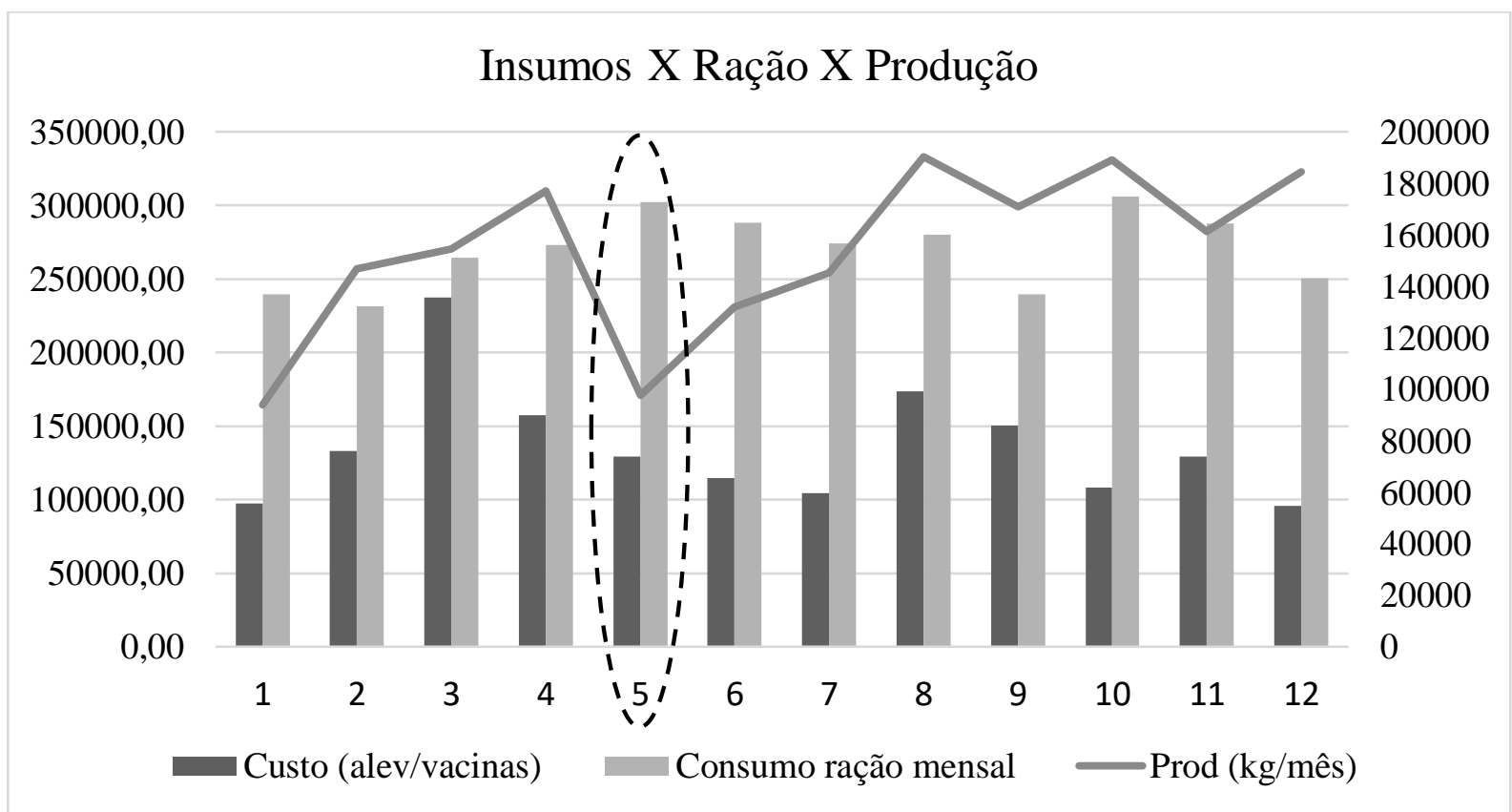

Fonte: Autoria própria. 
Os alvos das variáveis permitem informações ao produtor sobre a ineficiência e o que deve ser feito para alcançar a eficiência, ou seja, representam um valor referencial mínimo até o qual o empreendedor poderia reduzir os valores atuais correspondentes às variáveis. Neste sentido, tais informações são importantes para a uniformização de processos no ambiente de produção. Desta forma, considerando um conjunto de alternativas rotineiras de processo, conhecimentos de gestão técnica e econômica acerca do manejo da atividade são relevantes para um piscicultor.

\section{Discussão}

Convém mencionar que quando o sistema produtivo é medido apenas por um input e um output, a produtividade é medida pela razão entre o produto e o insumo. Entretanto, a eficiência expressa uma relação ótima entre recursos consumidos e produtos gerados entre diferentes DMU's avaliados. Segundo Belloni (2000), a eficiência produtiva associa à racionalidade econômica e produtividade material, com o propósito de uma empresa produzir um máximo de resultados com um mínimo de recursos, tais como insumos e taxa de conversão alimentar, que trabalhados de maneira racional, podem reduzir os custos no ciclo produtivo e otimizar o ciclo no que refere à nutrição animal.

Convém destacar que os cultivos mensais que alcançaram máxima eficiência total já otimizaram a produção total em relação aos insumos, e não podem reduzir a quantidade de inputs (insumos) sem que a produção (output) sofra uma contração. O modelo adotado (CCR), com orientação tanto adequada aos produtos como aos insumos, pressupõe que as unidades avaliadas operam com retornos constantes de escalas, sendo constituinte de grande parte dos setores produtivos com objetivo de otimizando sua produção (Vasconcellos \& Oliveira, 1996).

A análise dos alvos serve de suporte à produção, para que o gestor tenha referências na busca por formas de adequação e alcance dos objetivos necessários. Vale destacar que as folgas referem-se às quantidades extras a serem reduzidas nos insumos para que o produtor atinja o conjunto eficiência radial $^{4}$, após todos os insumos terem sido minimizados de maneira proporcional à produção (Surco, 2004).

Desta forma, os benefícios decorrentes dos ajustes das variáveis estudadas podem ser replicados para outros piscicultores, no sentido de contribuir com a gestão e controlar a produção anual de tilápias, sobretudo conhecendo-se algumas particularidades entre os meses eficientes ou não. Assim, como destacam Begnis, Estivalete e Silva (2007), torna-se essencial a formação do capital humano, uma vez que o profissional que atua no campo necessita de conhecimentos técnicos, que vão desde a produção agropecuária até o processamento, passando pelas áreas de conhecimento dos insumos, equipamentos e operação da unidade de produção agropecuária.

${ }^{4}$ Eficiência Radial $=$ alvo+folgas. 
Para a conversão alimentar, que relaciona o consumo de ração e o ganho de peso, quanto maior esta, maior o gasto com ração, sendo variável dependendo do sistema de produção. Kubitza (2004) retrata que as melhores conversões alimentares geralmente se encontram na faixa de 0,9 a 1,8.

Como fator contributivo e prático, a maioria dos trabalhos realizados mostram que os peixes irão crescer mais rápido e com melhor conversão alimentar aparente, quando o total de alimento (ração) oferecido é dividido em duas vezes ao dia, com pelo menos seis horas entre as alimentações (Roubach, 2002).

O conhecimento da devida frequência de arraçoamento proporciona melhor desempenho, já que altas taxas de alimentação interferem negativamente na qualidade da água (Salaro et al., 2008). Consequentemente, pode minimizar os custos com alimentação e manejo de limpeza dos tanques, reduzindo a possibilidade de problemas com a qualidade da água.

Quando o assunto é o custo de produção em aquicultura, um importante componente que chama a atenção é a ração. Este insumo representa de 65 a $80 \%$ dos custos totais de produção (com mais expressividade em Santa Fé do Sul/SP com 72\%, região do presente estudo); e desta forma, muitos piscicultores adotam diferentes estratégias de alimentação, testando diferentes tipos de ração. O importante destas avaliações é sempre considerar qualidade $x$ preço e seus impactos na eficiência (desempenho) produtivo e econômico (Barone, 2017).

Vale mencionar que o teor de proteína, junto com o preço da ração, é um dos parâmetros mais utilizados pelos piscicultores para avaliar a qualidade das rações comerciais (Roubach, 2002).

Segundo a FAO (2016), a geração de resíduos para o setor pesqueiro é um desafio, visto que cerca de $50 \%$ do volume processado diariamente é descartado em lixões, córregos, rios e mares, ocasionando impactos negativos ao ambiente. Entretanto, a reciclagem de resíduos apresenta-se como uma importante ferramenta para minimizar o déficit de fertilizantes orgânicos para sistemas produtivos ecológicos (Araújo, 2010). Como exemplo, a produção de farinha de peixe para alimentação, considerada a principal fonte de proteína dietética em rações para peixes, pode apresentar $70 \%$ de proteína (Feltes et al., 2010).

Quanto à geração de biomassa, a prática evidencia que quanto maior o consumo de ração, relacionado à frequência de alimentação e densidade de povoamento, reflete em maior biomassa total ao final de cada ciclo produtivo, relacionado também ao maior crescimento dos peixes. De acordo com Sousa et al. (2012), com o maior fracionamento da ração, as tilápias aproveitam melhor o alimento, melhorando seu desempenho produtivo.

Sharma et al (1999) destacam que uma orientação input, como foi proposto na orientação do modelo DEA do referido estudo, mede o desempenho em termos da redução máxima do uso dos insumos na produção de benefícios de quem produz. Desta forma, este trabalho demonstrou que a 
gestão otimizada infere na redução de custos operacionais, como exemplo, na disponibilidade adequada de ração a cada época do ano para um sistema intensivo de produção piscícola.

Neste sentido, o uso do DEA tem-se mostrado bastante atrativo em diversos setores de aplicação, como a produção animal, podendo apoiar as decisões dos produtores, ao indicar as fontes de ineficiência e aos melhores períodos que podem servir de referência às práticas adotadas (Gomes et al., 2003).

Por outro lado, conforme preconizam Dyson et al. (2001), algumas limitações da técnica DEA podem ser listadas, dentre elas a de que o DEA apenas analisa o desempenho relativo, convergindo muito vagarosamente para o desempenho absoluto, pelo fato de estar baseado em dados observados e não no ótimo ou no desejável. De forma auxiliar, a análise para mais de um ano poderá não somente medir a eficiência, mas também o índice de produtividade oriundo da tecnologia disponível no sistema produtivo.

\section{Considerações Finais}

Baseado nos resultados obtidos, pode-se concluir que o trabalho alcançou os objetivos que se propôs. Desta forma, é possível por meio de uma análise comparativa entre os meses de cultivo anual destacar níveis de eficiência, e a partir desses, tomar decisões ao produtor de maneira mais segura.

Neste sentido, a adoção de boas práticas zootécnicas poderá servir como diretriz ao gestor em sua atividade piscícola, como na otimização do consumo de ração relacionado à conversão alimentar, adequando a frequência e dosagem da ração não somente para cada fase de cultivo da tilápia, mas também em sua forma de aplicação adequada para cada época do ano, além do descarte possuir sua forma de aproveitamento sustentável, como parte constituinte da fabricação de rações.

A utilização da eficiência composta normalizada torna-se imprescindível para avaliação periódica na produção, de forma a categorizar um ranking na forma de desempate e determinar o melhor mês de cultivo dentro de uma análise periódica.

Esta técnica multicriterial contribui à tomada de decisão durante o processo de transformação de "insumos" em "produtos", refletindo que em cenários de eficiência ou ineficiência existem pessoas comprometidas com seus recursos, na expectativa de resultados positivos para a atividade piscícola.

Uma das lacunas existentes e que poderá ser competência de trabalhos futuros será a aplicação do índice de Malmquist, o qual este compara para dois ou mais períodos posteriores (considerando a disponibilidade de dados de produção), tornando-se uma ótima ferramenta para medir a mudança de produtividade de quem produz, bem como a alteração tecnológica e de eficiência, impossibilitada para a análise de apenas um único ano. 
Agradecimentos

À FAPESP (Fundação de Amparo à Pesquisa no Estado de São Paulo), pelo apoio neste trabalho, através do auxílio à pesquisa vigente.

\section{Referências}

Alves Junior, P. N; Melo, I. C., Celestini, G \& Rebelatto, D. A. D. N. (2018). Modelo de controle alocativo de Análise Envoltória de Dados (DEA) para avaliar sistemas de controle de estoque quando há relação entre as variáveis. Revista Gestão da Produção Operações e Sistemas, 13(1), p. 143. DOI: 10.15675/gepros.v13i1.1990

Angulo Meza, L.; Biondi Neto, L.; Soares de Mello, J.C.C.B. \& Gomes, E.G. (2005). ISYDS - Integrated System for Decision Support (SIAD - Sistema Integrado de Apoio à Decisão): a software package for data envelopment analysis model. Pesquisa Operacional, 25(3), p. 493- 503. https://doi.org/10.1590/S0101-74382005000300011

Ali, A. I. \& Seiford, L. M. (1993). The Mathematical Programming Approach to Efficiency Analysis. In: FRIED, H. O., LOVELL, C. A. K., SCHIMIDT, S. S. (Orgs.). The Measurement of Productive Efficiency: Techniques and Application. New York: Oxford University Press, cap. 3, p. 120-159.

Araújo, F. B. (2011). Avaliação de adubos orgânicos elaborados a partir de resíduo de pescado, na cultura do feijão (Phaseulos vulgaris). Pelotas, RS. Resumos do VII Congresso Brasileiro de Agroecologia, p. 1-5. Disponível em: <https://revistas.abaagroecologia.org.br/cad/article/view/12014/8282>. Acesso em: 19 set. 2022.

Araujo Neto, L. M. (2016). Eficácia, eficiência e produtividade dos gastos públicos municipais no Brasil. Dissertação (Mestrado em Administração), Universidade de Brasília, Brasília. 176 p. http://dx.doi.org/10.26512/2016.06.D.21284

Azambuja, A. M. V. (2002). Análise de Eficiência na Gestão do Transporte Urbano por Ônibus em Municípios Brasileiros. 385f. Tese (Doutorado em Engenharia de Produção) - Programa de Pós-Graduação em Engenharia de Produção, Universidade Federal de Santa Catarina, Florianópolis/SC. http://repositorio.ufsc.br/xmlui/handle/123456789/83123

Barone, R. S. C. (2017). Ração é o principal insumo da produção aquícola. CNA Brasil. Disponível em: $<$ https://www.cnabrasil.org.br/assets/arquivos/boletins/ativosaquicultura_0.90337400\%201514917005.pdf>. Acesso em: 14 set. 2020.

Begnis, H. S. M.; Estivalete, V. De F. B.; Silva, T. N. (2007). Formação e qualificação de capital humano para o desenvolvimento do agronegócio no Brasil. Informe Gepec, v. 11, n. 1, p. 1-10. DOI:https://doi.org/10.48075/igepec.v11i1.1095

Belloni, J. A. (2000). Uma metodologia de avaliação da eficiência produtiva de universidades federais brasileiras. 246f. Tese (Doutorado em Engenharia de Produção) - Universidade Federal de Santa Catarina, Florianópolis/SC. https://core.ac.uk/download/pdf/30359583.pdf

Bisso, C. S., Caldeira, J. F., Samanez, C. P., \& Telles, G. R. (2016). Produtividade e eficiência no mercado de fundos de investimento no Brasil: Uma abordagem comparativa. Revista Brasileira de Finanças, 14(3), p. 323-352. DOI: 10.12660/rbfin.v14n3.2016.58913 
Brunetta, M. R. (2004). Avaliação da eficiência técnica e de produtividade usando analise por envoltória de dados: um estudo de caso aplicado a produtores de leite. Dissertação (Mestrado em Métodos Numéricos em Engenharia), Universidade Federal do Paraná, Curitiba/PR. 101p. http://hdl.handle.net/1884/639

Casado, F. L. \& Siluk, J. C. M. (2011). Avaliação da Eficiência Técnica de Instituições Públicas Através da Utilização de Indicadores de Governança. In: XXXI Encontro Nacional de Engenharia de Produção. Belo Horizonte, MG.

https://abepro.org.br/biblioteca/enegep2011_tn_sto_135_855_18751.pdf

Charnes, A., Cooper, W. W. \& Rhodes, E. (1978). Measuring the efficiency of decision making units. European Journal of Operational Research, v.2, p.429-444. https://doi.org/10.1016/03772217(78)90138-8

Coelli, T. J. (1996). A guide to DEAP version 2.1: a data envelopment analysis program. Armidale, Austrália: University of New England. 49 p. https://www.owlnet.rice.edu/ econ380/DEAP.PDF

Dyson, R. G. \& Allen, R. \& Camanho, A. S. \& Podinovski, V. V. \& Sarrico, C. S. \& Shale, E. A. (2001). Pitfalls and protocols in DEA. European Journal of Operational Research, vol. 132(2), p. 245259. https://doi.org/10.1016/S0377-2217(00)00149-1

Embrapa. (2018). Dimensão socioeconômica da tilapicultura no Brasil. In: Barroso, R. M. ... [et al.], autores. Brasília, DF: Embrapa, 110 p. Disponível em: <https://ainfo.cnptia.embrapa.br/digital/bitstream/item/175109/1/CNPASA-2018Ivdimensao.pdf>. Acesso em: 19 Set. 2022.

Farrell, M. J. (1957). The Measurement of Productive Efficiency. Journal of the Royal Statistical Society. Series A (General), 120(3), p. 253-290. https://doi.org/10.2307/2343100

Feltes, M. C.M.; Correia, J. F. G.; Beirão, L. H.; Block, J. M., Ninow, J. L.; Spiller, V. R. (2010). Alternativas para a agregação de valor aos resíduos da industrialização de peixe. Revista Brasileira de Engenharia Agrícola e Ambiental, 14(6), p.669-677. https://doi.org/10.1590/S141543662010000600014

Gomes, E. G., Mangabeira, J. A. D. C. \& Mello, J. C. C. B. S. (2005). Análise de envoltória de dados para avaliação de eficiência e caracterização de tipologias em agricultura: um estudo de caso. Revista de Economia e Sociologia Rural, 43(4), p. 607-631. https://doi.org/10.1590/S010320032005000400001

Gomes, E. G.; Soares De Mello, J. C. C. B.; Biondi, L. N. (2003). Avaliação de Eficiência por Análise de Envoltória de Dados: conceitos, aplicações à agricultura e integração com sistemas de informação geográfica. - Campinas: Embrapa Monitoramento por Satélite, 39 p. https://www.infoteca.cnptia.embrapa.br/infoteca/handle/doc/17113

Jorge, M. J.; Carvalho, F. A; Jorge, M. F; Medeiros, R. O. (2010). Gestão orientada para resultado: um estudo sobre os hospitais navais da Marinha do Brasil. In: SEGeT - Simpósio de Excelência em Gestão e Tecnologia, 7.,Anais... Resende/RJ. Disponível em: <http://www.aedb.br/seget/artigos2008.php> Acesso em: 22 Set. 2022.

Kubitza, F. (2004). Qualidade da água, planejamento da produção, manejo nutricional e alimentar, sanidade em piscicultura. Jundiaí: F. Kubitza, 22p. 
Marconi, M. D. A. \& Lakatos, E. M. (1996). Técnicas de pesquisa: planejamento e execução de pesquisas, amostragens e técnicas de pesquisas, elaboração, análise e interpretação de dados. 3.ed. São Paulo: Atlas, 278 p.

Marinho, A. (2001). Estudo de eficiência em alguns hospitais públicos e privados com a geração de rankings. Texto para discussão n. 794. Rio de Janeiro: IPEA, 17p. http://repositorio.ipea.gov.br/handle/11058/2238

Matos, L. L. (1996). Perspectivas em alimentação e manejo de vacas em lactação. Embrapa - Centro Nacional de Pesquisa de Gado de Leite. Juiz de Fora: Embrapa Gado de Leite.

Oliveira, I. R. (2008). Utilização da análise envoltória de dados (DEA) no diagnóstico de eficiência de cultivo do camarão marinho Litopenaeus vannamei. 45f. Dissertação de mestrado, UFRPEPrograma de pós-graduação em Biometria e Estatística Aplicada, Recife, PE. http://www.tede2.ufrpe.br:8080/tede2/handle/tede2/5000

Paiva Junior, H. (2000). Avaliação de desempenho de ferrovias utilizando a abordagem integrada DEA/AHP. 178p. Dissertação (mestrado) - Universidade Estadual de Campinas, Faculdade de Engenharia Civil, Campinas, SP. DOI: https://doi.org/10.47749/T/UNICAMP.2000.197838

Peixe Br. (2019). Anuário estatístico da piscicultura. São Paulo: Associação Brasileira de Piscicultura, $148 \mathrm{p}$.

Pereira, C. N. \& Silveira, J. M. F. J. (2016). Análise Exploratória da Eficiência Produtiva das Usinas de Cana-de-açúcar na Região Centro-Sul do Brasil. Revista de Economia e Sociologia Rural, 54(1), p.147-166. https://doi.org/10.1590/1234-56781806-9479005401008

Pimentel-Gomes, F. (2009). Curso de estatística experimental. 15. ed., Piracicaba: Fealq, 451 p.

Prodanov, C. C; Freitas, E. C. F. (2013). Metodologia do trabalho científico (recurso eletrônico): métodos e técnicas de pesquisa e do trabalho acadêmico. 2a ed. Novo Hamburgo/RS: Feevale, 277p. https://aedmoodle.ufpa.br/pluginfile.php/291348/mod_resource/content/3/2.1-Ebook-Metodologia-do-Trabalho-Cientifico-2.pdf

Ribeiro, M. R.; Santos, J. P.; Silva, E. M.; Pereira-Júnior, E.; Tenório, Ma. A. S.; Lino E Silva, L.; Wehbi, M. D.; Lopes, J. P.; Tenório, R. A. (2015). A piscicultura nos reservatórios hidrelétricos do Submédio e Baixo São Francisco, região semiárida do Nordeste do Brasil. Acta Fish. Aquat. Res., v. 3, n.1, p. 91-108. https://doi.org/10.2312/Actafish.2015.3.1.91-108

Robach, R; Gomes, L. C; Chagas, E. C; Lourenço, J. N. P. (2002). Nutrição e manejo alimentar na piscicultura. Manaus: Embrapa Amazônia Ocidental, 14 p. http://www.infoteca.cnptia.embrapa.br/infoteca/handle/doc/674011

Salaro, A.L.; Luz, R.K.; Sakabe, R.; Kasai, R.Y.D. \& Lambertucci, D. M. (2008). Níveis de arraçoamento para juvenis de trairão (Hoplias lacerdae). Revista Brasileira de Zootecnia, 37(6), p.967-970. DOI:10.1590/S1516-35982008000600002

Sharma, K. R.; Leung, P. S.; Chen, H.; Peterson, A. (1999). Economic Efficiency and Optimum Stocking Densities in Fish Polyculture: an application of data envelopment analysis (DEA) to Chinese fish farms. Aquaculture. v. 180, p. 207-221. https://doi.org/10.1016/S0044-8486(99)00202-1 
Silva Neta, M. E. D; Lemos, J. J. S; Reis, J. N. P. \& Santos, S. M. (2016). Piscicultura no Açude Castanhão em Jaguaribara Ceará: Uma Avaliação Econômica, Social e Ambiental. 72f. Dissertação. Programa de pós-graduação em Economia Rural, UFC, Fortaleza/CE. http://www.repositorio.ufc.br/handle/riufc/19396

Sousa, R. M. R.; Agostinho, C. A; Oliveira, F. A; Argentim, D. (2012). Productive performance of Nile tilapia (Oreochromis niloticus) fed at different frequencies and periods with automatic dispenser. Arq. Bras. Med. Vet. Zootec., v.64, n.1, p.192-197. https://doi.org/10.1590/s010209352012000100027

Surco, D. F. (2004). Desenvolvimento de uma ferramenta computacional para avaliação de eficiência técnica baseada em DEA. Dissertação. 129f. (Mestrado em Métodos numéricos em engenharia). UFPR. Curitiba. http://hdl.handle.net/1884/3150

Sussel, F. R. (2015). Cadeia produtiva da tilápia. Boletim Ativos da Aquicultura-CNA Brasil, n. 3, p. 4.

Sussel, F. R. (2011). Tilapicultura no Estado de São Paulo. Pesquisa \& Tecnologia - Artigo Técnico do Polo Regional Centro Leste/APTA, p. 1-4. Disponível em:

<http://www.aptaregional.sp.gov.br/acesse-os-artigos-pesquisa-e-tecnologia/edicao2011/2011-julho-dezembro/867-tilapicultura-no-estado-de-sao-paulo/file.html>. Acesso em: 19 Set. 2022.

Torres, S. M., Pereira, F. D. A. R., Souza, C. C. \& Ferreira, M. B. (2017). Análise da eficiência da produção da piscicultura na região de Dourados-MS. Espacios, 38(52), p. 26-42. DOI: 10.48082/espacios-a17v38n52p26

Vasconcellos, M. A. S. \& Oliveira, R. G. (1996). Manual de Microeconomia. São Paulo: Atlas. 318p.

Zubyk, A. R.; Ribeiro, F.; Clemente, A. \& Gerigk, W. (2019). Eficiência na gestão dos gastos municipais em educação e de saúde: um estudo baseado na análise envoltória de dados no Estado do Paraná. Enfoque Reflexão Contábil, 38(1), p.123-139. https://doi.org/10.46551/epp2021923 